\title{
Comparison Of Apo B/A1, Lipoprotein (A) And LDL- C/Apo B For Predicting Coronary Atherosclerosis In Patients $\leq 65$ Years With Low LDL-C
}

Hae Won Jung

Daegu Catholic University Medical Center

Han Joon Bae

Daegu Catholic University Medical Center

Seung-Pyo Hong ( $\square$ sphong@cu.ac.kr)

Daegu Catholic University Medical Center

\section{Research Article}

Keywords:

Posted Date: February 11th, 2022

DOI: https://doi.org/10.21203/rs.3.rs-1288793/v1

License: (c) (i) This work is licensed under a Creative Commons Attribution 4.0 International License.

Read Full License 


\section{Abstract}

Background: High low-density lipoprotein cholesterol (LDL-C) and old age are major risk factors for coronary artery disease. However, the risk factors for coronary artery disease in relatively young patients with low LDL-C have not been elucidated. Therefore, we performed this study to evaluate the risk factors of coronary artery disease, in patients under 65 years with low LDL-C.

Methods: This study included 622 lipid-lowering agent naive patients $\leq 65$ years with LDL-C $<127.5$ $\mathrm{mg} / \mathrm{dL}$ who underwent coronary computed tomographic angiography. We performed multivariate logistic regression analysis to evaluate the risk factors of coronary atherosclerosis, defined as the presence of coronary plaque. In addition to traditional cardiovascular risk factors, the covariate included novel lipid profiles (apolipoprotein (Apo) B/Apo A1) ratio, LDL-C/Apo B ratio, and lipoprotein (a)).

Results: Of the total 622 patients, the mean age was $54.4 \pm 8.9$ and the mean LDL-C was $91.0 \pm 23.1$ $\mathrm{mg} / \mathrm{dL}$. Multivariate regression analysis showed that age, male, diabetes mellitus, and hypertension were independent predictors of coronary atherosclerosis. A high LDL-C/Apo B ratio was a negative predictor of coronary atherosclerosis.

Conclusions: A low LDL-C/Apo B ratio is associated with the development of coronary atherosclerosis in patients $\leq 65$ years with low LDL-C levels.

\section{Introduction}

High low-density lipoprotein cholesterol (LDL-C) and old age are major risk factors for coronary artery disease [1-4]. Won et al. reported that age $\geq 65$ years, LDL-C level $\geq 127.5 \mathrm{mg} / \mathrm{dL}$, and male sex were the major risk factors for subclinical coronary atherosclerosis in patients without traditional cardiovascular risk factors [1]. However, risk factors for coronary artery disease in relatively young patients and low LDLC have not been elucidated. In addition, the apolipoprotein (Apo) B)/Apo A1 ratio, lipoprotein (a) (Lp (a)) level, and LDL-C/Apo B ratio have been useful for predicting atherosclerotic cardiovascular disease (ASCVD) and mortality [5-10]. However, it is not known whether these novel lipid profiles are better predictors of coronary artery disease in relatively young patients with low LDL-C compared to the conventional lipid profiles. Therefore, we performed this study to evaluate the risk factors of coronary artery disease, including traditional cardiovascular risk factors, and novel lipid profiles, in patients under 65 years with LDL-C $<127.5 \mathrm{mg} / \mathrm{dL}$.

\section{Methods}

\section{Study population and data collection}

The study population was selected from the coronary computed tomographic angiography (CCTA) registry of the Daegu Catholic Medical Center (Daegu, Korea). Between January 2013 and September 2020, 3,696 patients who visited our hospital for chest discomfort underwent CCTA and lipid profile 
evaluation (total cholesterol (TC), LDL-C, high-density lipoprotein cholesterol (HDL-C), triglyceride (TG), APO A1, APO B, and Lp (a)). Among the 3,696 patients, 1,162 patients were $\leq 65$ years and had LDL-C levels $<127.5 \mathrm{mg} / \mathrm{dL}$. Of the 1,162 patients, 298 patients who underwent percutaneous coronary intervention $(\mathrm{PCl})$ or cardiac surgery, 217 patients who were maintained on lipid-lowering drugs, 20 patients with end-stage renal disease, and 5 patients with motion artifacts on CCTA were excluded. Finally, 622 patients were included in the analysis. The inclusion and exclusion criteria are shown in a flow diagram (Figure 1).

\section{Acquisition and analysis of CCTA images}

CT scans were performed with a 256-slice CT (Definition Flash; Siemens Healthineers AG) or a 512-slice CT (Revolution CT; GE Healthcare). All patients with an initial heart rate $\geq 60$ beats/min were given an oral beta-blocker (propranolol $20 \mathrm{mg}$ ) to achieve a target heart rate of 50 to 60 beats/min. Sublingual nitroglycerin was administered immediately before scanning. An iodine contrast agent $(60-70 \mathrm{~mL})$ was administered into the antecubital vein within 10 seconds followed by $25 \mathrm{~mL}$ of saline solution injected at $5.0 \mathrm{~mL} /$ second. The CT-reconstructed imaging data were transferred to a GE Centricity system (GE Healthcare Bio-Sciences Corp) for postprocessing and subsequent image analysis. A radiologist read each scan independently at a central reading center. Atherosclerosis was defined as the presence of coronary plaque. Plaques were defined as structures $\geq 1 \mathrm{~mm} 2$ within and/or adjacent to the vessel lumen and were clearly distinguishable from the lumen and the surrounding pericardial tissue [1]. Stenosis of $50 \%$ or more in one vessel was defined as 1 vessel disease, and stenosis of $50 \%$ or more in two or more vessels was defined as multivessel disease. The coronary artery calcium score (CACS) was acquired with the Agatston method using a commercially available reconstruction program for three-dimensional reconstruction and measurement (Aquarius iNtuition TM Ver.4.4.12 TeraRecon) [11, 12]. CACS $>0$ was defined as having a detectable coronary artery calcium [13]. After CCTA evaluation, coronary revascularization ( $\mathrm{PCl}$ or coronary artery bypass graft (CABG)) was performed according to the judgment of the attending physician. The coronary revascularization rate was investigated. All methods were performed in accordance with the relevant guidelines and regulations.

\section{Statistical analysis}

Data were expressed as number (\%) and mean \pm standard deviation. Categorical data were compared using the Chi-square test or Fisher's exact test. Continuous variables were compared using the Student's ttest and Kruskal-Wallis $\mathrm{H}$ test when they were normally and non-normally distributed, respectively. Univariate analysis using logistic regression was performed to identify potential independent predictors for coronary atherosclerosis. Age, sex, and variables with a p-value $<0.05$ in the univariate analysis were included in the multivariate analysis to determine the independent predictors for coronary atherosclerosis. Diagnostic accuracy of lipid profiles on a continuous scale in the prediction of coronary atherosclerosis was estimated as the area under the curve (AUC) from receiver operating characteristic (ROC) curves. Univariate analysis using logistic regression was performed to identify potential independent predictors of the lowest tertile of the LDL-C/Apo B ratio. Age, sex, and variables with a $p$-value $<0.05$ were included in 
the multivariate logistic regression analysis. Pearson's correlation analysis was used to assess the correlations between various parameters and the LDL-C/Apo B ratio. A p-value $<0.05$ was considered statistically significant. Statistical analyses were performed using SPSS version 25.0 (IBM, Armonk, NY, USA).

\section{Results}

Of the total 622 patients, the mean age was $54.4 \pm 8.9$ years and the mean LDL-C level was $91.0 \pm 23.1$ $\mathrm{mg} / \mathrm{dL}$. $63.2 \%$ were male and $23.2 \%$ had diabetes. Coronary revascularization was performed in $13 \%$. Atherosclerosis, defined as the presence of coronary plaque, was present in $61.1 \%$ of the total patients. The clinical characteristics of the patients according to presence of plaque are shown in Table 1. In the plaque group compared to the no plaque group, age and fasting blood glucose were significantly higher, and estimated glomerular filtration rate and body mass index were significantly lower. The proportion of male, diabetes mellitus, hypertension, and smoking patients were significantly higher in the plaque group compared to the no plaque group. In the comparison of lipid profiles, the plaque group showed significantly lower TC, HDL-C, Apo A1, and LDL-C/ Apo B ratio compared to the no plaque group. Lp (a) was significantly higher in the plaque group compared to the no plaque group.

\section{Independent predictors of atherosclerosis}

According to the multivariate logistic regression analysis, age (odds ratio (OR): 1.108; $95 \%$ confidence interval (Cl): 1.076-1.140, p<0.001), male sex (OR: 3.912; 95\% Cl: 2.443-6.264, $\mathrm{p}<0.001$ ), diabetes mellitus (OR: 2.354; 95\% Cl: 1.369-4.048, p=0.002) and hypertension (OR: 2.260; 95\% Cl: 1.446-3.532, $\mathrm{p}<0.001)$ were significantly associated with coronary atherosclerosis. Meanwhile, a high LDL-C/Apo $B$ ratio was a negative predictor of coronary atherosclerosis (OR: $0.277 ; 95 \% \mathrm{Cl}: 0.077-0.994, p=0.049$ ) (Table 2). According to the ROC analyses, the best predictive value for coronary atherosclerosis was an LDL-C/Apo B ratio $\leq 1.106$ (AUC=0.598 p=0.000; sensitivity, 57.0\%; specificity, 57.4\%). The AUC for the LDL-C/Apo $B$ ratio was larger than that of the Apo B/Apo A1 ratio and HDL-C, LDL-C, Lp (a), and TG (Apo B/Apo A1 ratio: $A U C=0.540, p=0.096 ;$ HDL-C: $A U C=0.583, p<0.001 ;$ LDL-C: $A U C=0.455, p=0.057 ;$ Lp (a): $A U C=0.522, p=0.351 ; T G: A U C=0.565, p=0.007$ )

\section{Characteristics according to tertiles of the LDL-C/Apo B ratio}

The clinical characteristics of the patients stratified by tertiles of the LDL-C/Apo B ratio are shown in Table 3. The cut-off points between tertiles were 1.0275 (between the first and second tertile) and 1.1666 (between the second and third tertile). The averages of the LDL-C/Apo B ratio of tertiles 1, 2, and 3 was $0.908 \pm 0.126,1.099 \pm 0.039$, and $1.268 \pm 0.095$, respectively. In tertile 1 , there was significantly more male and diabetic patients than in the other 2 tertiles. Fasting blood glucose was significantly higher in tertile 1 than in the other 2 tertiles. In terms of CCTA characteristics, the proportion of patients with CAC exceeding 0 , plaque, and multivessel disease were significantly higher in tertile 1 than in the other 2 tertiles. After CCTA, more coronary revascularization was performed in tertile 1 compared to the other 2 tertiles. 


\section{Independent predictors of the lowest tertile for the LDL-C/Apo B ratio}

In the multivariate logistic regression analysis, diabetes mellitus (OR: 1.816; 95\% Cl: 1.196-2.756, $p=0.005)$ and hypertriglyceridemia (OR: 1.006; $95 \% \mathrm{Cl}: 1.003-1.008, p<0.001)$ were the independent predictors of the lowest tertile for the LDL-C/Apo B ratio (Table 4).

\section{Correlation analysis between variables and the LDL-C/Apo B ratio}

The results of Pearson's correlation analysis between the LDL-C/ Apo B ratio and other clinical factors are presented in Supplementary Table 1. TG and HDL levels had the strongest correlation with the LDL-C/Apo $B$ ratio (TG: correlation coefficient $=-0.291, p<0.001$; HDL-C: correlation coefficient $=0.291, p<0.001$ ) as depicted in Figure 2.

\section{Discussion}

The primary findings of present study were as follows: 1) A low LDL-C/Apo B ratio was an independent predictor of coronary atherosclerosis in patients $\leq 65$ years with low LDL cholesterol; 2 ) The LDL-C/Apo B ratio demonstrated a greater predictive accuracy for coronary atherosclerosis compared with other lipid profiles, including Apo B/Apo A1 ratio and Lp (a), in patients < 65 years with low LDL cholesterol; 3 ) Diabetes mellitus and hypertriglyceridemia were significantly associated with a low LDL-C/Apo $B$ ratio.

Currently, lowering the LDL-C is the main treatment strategy to prevent ASCVD [14-15]; however, ASCVD still occurs in patients with low LDL-C. Therefore, studies on lipoproteins to evaluate residual cardiovascular risk in patients with low LDL-C are ongoing. In this study, the LDL-C/Apo B ratio was an independent predictor of coronary atherosclerosis. On the other hand, Apo B/Apo A1 and Lp (a) did not predict coronary atherosclerosis and showed a lesser predictive accuracy for coronary atherosclerosis compared with the LDL-C/Apo B ratio. In previous studies, the LDL-C/Apo B ratio has been identified as a marker of small dense low-density lipoprotein (sdLDL). Several papers have reported that sdLDL increases the risk of ASCVD [16-18]. Increased atherogenesis of sdLDL is associated with specific biochemical properties of these particles. The small size makes penetration into the arterial wall easier, and smaller LDL particles have decreased receptor mediated uptake. Therefore, the half-life of sdLDL is longer than that of large LDL particles. A longer circulation time increases the possibility of atherogenic modifications of sdLDL in the blood [19, 20]. Hirano et al. found that an LDL-C/Apo B ratio of 1.2 corresponds to an LDL diameter of $25.5 \mathrm{~nm}$, which has been proposed as a cut-off value between sdLDL and large buoyant LDL [21]. In our study, the best predictive value for coronary atherosclerosis was an LDL-C/Apo B ratio $\leq 1.106$. This difference seems to be due to the difference between the biochemical and clinical values.

A low LDL-C/Apo B ratio has been associated with increased cardiovascular events $[9,10]$. In our study, the proportion of patients with CAC exceeding 0 , with multivessel disease, and who underwent revascularization were highest in the lowest tertile of the LDL-C/Apo B ratio. These results suggest that 
sdLDL affects not only the occurrence of plaque but also its severity which are consistent with the findings of Koba et al [22].

This study focused on the role of sdLDL in coronary atherosclerosis in patients with LDL-C $<127.5$ $\mathrm{mg} / \mathrm{dL}$. In Heinz's paper, subgroup analysis according to the LDL-C level showed that sdLDL was an independent predictor for major cardiovascular events only in the group with LDL-C below $121 \mathrm{mg} / \mathrm{dL}$ but not above $121 \mathrm{mg} / \mathrm{dL}$ [10]. These findings suggest that the impact of sdLDL on coronary atherosclerosis is greater in patients with low LDL-C than in patients with high LDL-C. Meanwhile, previous articles revealed that the ASCVD risk associations with Lp (a) are attenuated with low LDL-C [7,23]. Thus, different types of lipid profiles may better represent residual cardiovascular risk depending on a patient's LDL-C level.

The LDL-C/Apo B ratio cutoff value of 1.106 in this study is much lower than the cutoff value of 1.46 suggested by Heinz et al. [10], indicating that the primary endpoints in our study were less sensitively affected by the LDL-C/Apo $B$ ratio as compared to their study. The difference in the cutoff values of the LDL-C/Apo $B$ ratio between the two studies could be due to the following reasons. First, Heinz et al. conducted a study on patients with coronary artery disease and peripheral artery disease; in contrast, our study was for patients who had never been diagnosed with coronary artery disease. Second, there were no restrictions on the age or LDL-C in the study of Heinz et al. The cut-off value of the LDL-C/Apo B ratio may vary depending on the target patient group. A larger study is necessary to determine a universal clinical cut-off value of the LDL-C/Apo B ratio.

Previous studies have demonstrated a high sdLDL level is associated with hypertriglyceridemia, metabolic syndrome, and diabetes [24-27]. As in previous studies, in our study, diabetes mellitus (OR: 1.816; 95\% Cl: 1.196-2.756, $\mathrm{p}=0.005$ ) and hypertriglyceridemia (OR: $1.006 ; 95 \% \mathrm{Cl}: 1.003-1.008$, $p<0.001)$ were independent predictors of lowest tertile of the LDL-C/Apo B ratio. Treatment criteria for sdLDL are not yet clear. However, in patients with diabetes or hypertriglyceridemia, clinicians can additionally measure the LDL-C/Apo B ratio to further reduce the cardiovascular risk of patients even after satisfying the LDL-C target. Medications to reduce sdLDL have already been reported. Bahadir et al. reported significant reduction of the sdLDL after statin in hypercholesterolemic patients with metabolic syndrome [28]. In addition to statin, triglyceride-lowering treatments such as fibrates and omega-3 fatty acids, can be considered in patients with the high sdLDL since the formation of sdLDL is associated with hypertriglyceridemia $[29,30]$.

This study has strengths. First, this study is the first to compare the effects of Apo B/Apo A1, Lp (a), and LDL-C/Apo B on coronary atherosclerosis in patients with low LDL-C. Second, unlike previous studies that reported the relationship between the LDL-C/Apo B ratio and cardiovascular events [9,10], our study reports the relationship between the LDL-C/Apo $B$ ratio and the coronary plaque. Third, the present study was conducted on relatively young patients. Therefore, we investigated the role of the LDL-C/Apo B ratio in the early stages of atherosclerosis. However, this study has limitation. First, this was a single-center study. Second, the study population were comprised of Korean; studies with other races are necessary to 
confirm and generalize our findings. Third, because our study targeted patients who underwent CCTA for chest discomfort, the plaque incidence was high. Therefore, in order to apply the results of this study to the general population, a large-scale study including asymptomatic patients should be conducted.

\section{Declarations}

\section{Ethics approval and consent to participate.}

The protocol of the present study was approved by the institutional review board of daegu catholic university medical center. The institutional review board of daegu catholic university medical center waived the requirement for patient informed consent because of the study's retrospective nature.

\section{Data availability}

All data generated or analyzed during this study are included in this published article

\section{Author contributions}

All authors have made substantial contributions. H.W.J. and H.J.B. performed the statistical analysis. H.W.J. and H.J.B. contributed to data acquisition. H.W.J. and H.J.B. contributed to the interpretation of data. H.W.J. drafted the manuscript. S.P.H. critically revised the manuscript. All authors read and approved the final manuscript. All authors also gave final approval and agree to be accountable for all aspects of work ensuring integrity and accuracy.

\section{Funding}

This work was supported by research grant from Daegu Catholic University Medical Center

\section{Competing interests}

The authors declare no competing interests.

\section{Conclusion}

A low LDL-C/Apo B ratio is significantly associated with the development of coronary atherosclerosis in patients $\leq 65$ years with low LDL-C levels. These findings support the need for detection and treatment of a low LDL-C/Apo $B$ ratio for preventing the development of coronary atherosclerosis in relatively young patients with low LDL-C.

\section{References}

1. Won, K. B. et al. Independent role of low-density lipoprotein cholesterol in subclinical coronary atherosclerosis in the absence of traditional cardiovascular risk factors. Eur Heart J Cardiovasc Imaging 20, 866-872, doi:10.1093/ehjci/jez091 (2019). 
2. The impact of cardiovascular risk factors on the age-related excess risk of coronary heart disease. Int J Epidemiol 35, 1025-1033, doi:10.1093/ije/dyl058 (2006).

3. Abdullah, S. M. et al. Long-Term Association of Low-Density Lipoprotein Cholesterol With Cardiovascular Mortality in Individuals at Low 10-Year Risk of Atherosclerotic Cardiovascular Disease. Circulation 138, 2315-2325, doi:doi:10.1161/CIRCULATIONAHA.118.034273 (2018).

4. Mortensen, M. B. \& Nordestgaard, B. G. Elevated LDL cholesterol and increased risk of myocardial infarction and atherosclerotic cardiovascular disease in individuals aged $70-100$ years: a contemporary primary prevention cohort. Lancet $396,1644-1652$, doi:10.1016/s01406736(20)32233-9 (2020).

5. Walldius, G. et al. High apolipoprotein B, low apolipoprotein A-I, and improvement in the prediction of fatal myocardial infarction (AMORIS study): a prospective study. Lancet 358, 2026-2033, doi:10.1016/s0140-6736(01)07098-2 (2001).

6. McQueen, M. J. et al. Lipids, lipoproteins, and apolipoproteins as risk markers of myocardial infarction in 52 countries (the INTERHEART study): a case-control study. Lancet 372, 224-233, doi:10.1016/s0140-6736(08)61076-4 (2008).

7. Afshar, M. et al. Risks of Incident Cardiovascular Disease Associated With Concomitant Elevations in Lipoprotein(a) and Low-Density Lipoprotein Cholesterol-The Framingham Heart Study. Journal of the American Heart Association 9, e014711, doi:10.1161/JAHA.119.014711 (2020).

8. Langsted, A., Kamstrup, P. R. \& Nordestgaard, B. G. High lipoprotein(a) and high risk of mortality. European Heart Journal 40, 2760-2770, doi:10.1093/eurheartj/ehy902 (2019)

9. Rabizadeh, S. et al. LDL/Apo B ratio Predict Coronary Heart Disease in Type2 Diabetes Independent of ASCVD Risk Score: A Case-Cohort Study. Nutrition, Metabolism and Cardiovascular Diseases 31, doi:10.1016/j.numecd.2021.01.013 (2021).

10. Drexel, H. et al. The LDL-C/ApoB ratio predicts major cardiovascular events in patients with established atherosclerotic cardiovascular disease. Atherosclerosis 329, 44-49, doi:10.1016/j.atherosclerosis.2021.05.010 (2021).

11. Agatston, A. S. et al. Quantification of coronary artery calcium using ultrafast computed tomography. Journal of the American College of Cardiology 15, 827-832, doi:https://doi.org/10.1016/07351097(90)90282-T (1990).

12. Lee, S. Y. et al. Feasibility of Coronary Artery Calcium Scoring on Dual-Energy Chest Computed Tomography: A Prospective Comparison with Electrocardiogram-Gated Calcium Score Computed Tomography. J Clin Med 10, doi:10.3390/jcm10040653 (2021).

13. Chung, Y. H. et al. Coronary calcification is associated with elevated serum lipoprotein (a) levels in asymptomatic men over the age of 45 years: A cross-sectional study of the Korean national health checkup data. Medicine (Baltimore) 100, e24962, doi:10.1097/md.0000000000024962 (2021).

14. Mach, F. et al. 2019 ESC/EAS Guidelines for the management of dyslipidaemias: lipid modification to reduce cardiovascular risk: The Task Force for the management of dyslipidaemias of the European 
Society of Cardiology (ESC) and European Atherosclerosis Society (EAS). European Heart Journal 41, 111-188, doi:10.1093/eurheartj/ehz455 (2020).

15. Grundy, S. M. et al. 2018 AHA/ACC/AACVPR/AAPA/ABC/ACPM/ADA/AGS/APhA/ASPC/NLA/PCNA Guideline on the Management of Blood Cholesterol: A Report of the American College of Cardiology/American Heart Association Task Force on Clinical Practice Guidelines. Circulation 139, e1082-e1143, doi:10.1161/CIR.0000000000000625 (2019).

16. St-Pierre, A. C. et al. Low-Density Lipoprotein Subfractions and the Long-Term Risk of Ischemic Heart Disease in Men. Arteriosclerosis, Thrombosis, and Vascular Biology 25, 553-559, doi:10.1161/01.ATV.0000154144.73236.f4 (2005).

17. Duran, E. K. et al. Triglyceride-Rich Lipoprotein Cholesterol, Small Dense LDL Cholesterol, and Incident Cardiovascular Disease. J Am Coll Cardiol 75, 2122-2135, doi:10.1016/j.jacc.2020.02.059 (2020).

18. Jin, J.-L. et al. Association of small dense low-density lipoprotein with cardiovascular outcome in patients with coronary artery disease and diabetes: a prospective, observational cohort study. Cardiovascular Diabetology 19, 45, doi:10.1186/s12933-020-01015-6 (2020).

19. Berneis, K. K. \& Krauss, R. M. Metabolic origins and clinical significance of LDL heterogeneity. J Lipid Res 43, 1363-1379, doi:10.1194/jlr.r200004-j|r200 (2002).

20. Ivanova, E. A., Myasoedova, V. A., Melnichenko, A. A., Grechko, A. V. \& Orekhov, A. N. Small Dense Low-Density Lipoprotein as Biomarker for Atherosclerotic Diseases. Oxid Med Cell Longev 2017, 1273042, doi:10.1155/2017/1273042 (2017).

21. Hirano, T., Ito, Y. \& Yoshino, G. Measurement of small dense low-density lipoprotein particles. J Atheroscler Thromb 12, 67-72, doi:10.5551/jat.12.67 (2005).

22. Koba, S. et al. Significance of small dense low-density lipoprotein-cholesterol concentrations in relation to the severity of coronary heart diseases. Atherosclerosis $189,206-214$, doi:10.1016/j.atherosclerosis.2005.12.002 (2006).

23. Verbeek, R. et al. Cardiovascular disease risk associated with elevated lipoprotein(a) attenuates at low low-density lipoprotein cholesterol levels in a primary prevention setting. Eur Heart J 39, 25892596, doi:10.1093/eurheartj/ehy334 (2018).

24. Suh, S. et al. Smaller Mean LDL Particle Size and Higher Proportion of Small Dense LDL in Korean Type 2 Diabetic Patients. Diabetes Metab J 35, 536-542, doi:10.4093/dmj.2011.35.5.536 (2011).

25. Blackburn, P. et al. Impact of postprandial variation in triglyceridemia on low-density lipoprotein particle size. Metabolism 52, 1379-1386, doi:10.1016/s0026-0495(03)00315-9 (2003).

26. Tan, K. C. et al. Fasting and postprandial determinants for the occurrence of small dense LDL species in non-insulin-dependent diabetic patients with and without hypertriglyceridaemia: the involvement of insulin, insulin precursor species and insulin resistance. Atherosclerosis 113, 273287, doi:10.1016/0021-9150(94)05454-q (1995)

27. Gazi, I. et al. Concentration and relative distribution of low-density lipoprotein subfractions in patients with metabolic syndrome defined according to the National Cholesterol Education Program 
criteria. Metabolism 55, 885-891, doi:10.1016/j.metabol.2006.02.015 (2006).

28. Bahadir, M. A., Oguz, A., Uzunlulu, M. \& Bahadir, O. Effects of different statin treatments on small dense low-density lipoprotein in patients with metabolic syndrome. J Atheroscler Thromb 16, 684690, doi:10.5551/jat.1123 (2009).

29. Tokuno, A. et al. The Effects of Statin and Fibrate on Lowering Small Dense LDL-Cholesterol in Hyperlipidemic Patients with Type 2 Diabetes. Journal of Atherosclerosis and Thrombosis 14, 128132, doi:10.5551/jat.14.128 (2007).

30. Lee, M. W. et al. Beneficial Effects of Omega-3 Fatty Acids on Low Density Lipoprotein Particle Size in Patients with Type 2 Diabetes Already under Statin Therapy. Diabetes Metab J 37, 207-211, doi:10.4093/dmj.2013.37.3.207 (2013).

\section{Tables}

Table 1. Characteristics of individuals according to presence of plaque. 
Variables

Total patients No plaque

Plaque

p-value

$(n=622) \quad(n=242) \quad(n=380)$

Clinical characteristics

\begin{tabular}{|c|c|c|c|c|}
\hline Age, years & $54.4 \pm 8.9$ & $49.9 \pm 10.5$ & $57.2 \pm 6.3$ & $<0.001$ \\
\hline Male & $393(63.2)$ & $107(44.2)$ & $286(75.3)$ & $<0.001$ \\
\hline Diabetes & $144(23.2)$ & $27(11.2)$ & $117(30.8)$ & $<0.001$ \\
\hline Hypertension & $240(38.6)$ & $61(25.2)$ & $179(47.1)$ & $<0.001$ \\
\hline Smoking & $208(33.4)$ & $64(26.4)$ & $144(37.9)$ & 0.003 \\
\hline SBP (mmHg) & $126.1 \pm 18.0$ & $124.9 \pm 18.2$ & $126.8 \pm 17.8$ & 0.189 \\
\hline $\mathrm{DBP}(\mathrm{mmHg})$ & $75.6 \pm 12.1$ & $75.2 \pm 13.0$ & $75.8 \pm 11.6$ & 0.534 \\
\hline $\mathrm{BMI}\left(\mathrm{kg} / \mathrm{m}^{2}\right)$ & $24.4 \pm 3.64$ & $24.9 \pm 4.23$ & $24.1 \pm 3.19$ & 0.017 \\
\hline $\begin{array}{l}\text { eGFR } \\
\left(\mathrm{ml} / \mathrm{min} / 1.73 \mathrm{~m}^{2}\right)\end{array}$ & \multicolumn{3}{|c|}{$\left(\mathrm{ml} / \mathrm{min} / 1.73 \mathrm{~m}^{2}\right)$} & $<0.001$ \\
\hline EF (\%) & $56.3 \pm 12.2$ & $56.7 \pm 12.1$ & $56.1 \pm 12.3$ & 0.560 \\
\hline Fasting blood glucose & $114.4 \pm 44.5$ & $107.3 \pm 44.6$ & $118.8 \pm 44.0$ & 0.002 \\
\hline \multicolumn{5}{|l|}{ Lipid profile } \\
\hline $\mathrm{TC}(\mathrm{mg} / \mathrm{dL})$ & $150.6 \pm 27.0$ & $153.7 \pm 26.1$ & $148.7 \pm 27.4$ & 0.028 \\
\hline TG (mg/dL) & $121.1 \pm 92.5$ & $112.4 \pm 89.5$ & $126.6 \pm 94.1$ & 0.069 \\
\hline HDL-C (mg/dL) & $46.9 \pm 15.2$ & $49.3 \pm 15.7$ & $45.3 \pm 14.6$ & 0.001 \\
\hline LDL-C (mg/dL) & $91.0 \pm 23.1$ & $93.2 \pm 21.9$ & $89.6 \pm 23.7$ & 0.056 \\
\hline Lp (a) (mg/dL) & $20.8 \pm 24.8$ & $18.3 \pm 20.0$ & $22.4 \pm 27.3$ & 0.046 \\
\hline Apo B (mg/dL) & $83.5 \pm 18.5$ & $83.4 \pm 17.2$ & $83.7 \pm 19.4$ & 0.835 \\
\hline Apo A1 (mg/dL) & $128.4 \pm 30.1$ & $132.2 \pm 28.8$ & $126.0 \pm 30.7$ & 0.012 \\
\hline Apo B/Apo A1 & $0.695 \pm 0.267$ & $0.665 \pm 0.216$ & $0.714 \pm 0.294$ & 0.026 \\
\hline LDL-C/Apo B & $1.091 \pm 0.174$ & $1.12 \pm 0.178$ & $1.07 \pm 0.169$ & 0.001 \\
\hline
\end{tabular}

Data are given as mean $\pm S D$, or as number (\%). Apo A1; apolipoprotein A1, Apo B; apolipoprotein B, BMl; body mass index, CACS; coronary artery calcium score, CCTA; coronary computed tomographic angiography, EF; ejection fraction, eGFR; estimated glomerular filtration rate, HDL-C; high-density lipoprotein cholesterol, LDL-C; low-density lipoprotein cholesterol, Lp (a); lipoprotein (a), TC; total cholesterol, TG; triglyceride 
Table 2. Independent predictors for coronary atherosclerosis.

\begin{tabular}{|lllllll|}
\hline Variables & \multicolumn{3}{c}{ Univariate analysis } & & & Multivariate analysis \\
\hline Age & OR & $95 \%$ Cl & p-value & OR & $95 \%$ Cl & p-value \\
\hline Male & 1.112 & $1.086-1.138$ & $<0.001$ & 1.108 & $1.076-1.140$ & $<0.001$ \\
\hline Diabetes & 3.839 & $2.720-5.417$ & $<0.001$ & 3.912 & $2.443-6.264$ & $<0.001$ \\
\hline Hypertension & 2.542 & $2.246-5.587$ & $<0.001$ & 2.354 & $1.369-4.048$ & 0.002 \\
\hline Smoking hx & 1.697 & $1.1956-3.762$ & $<0.001$ & 2.260 & $1.446-3.532$ & $<0.001$ \\
\hline BMI & 0.948 & $0.906-0.991$ & 0.018 & 0.946 & $0.889-1.006$ & 0.935 \\
\hline SBP & 1.006 & $0.997-1.015$ & 0.189 & & & 0.077 \\
\hline DBP & 1.004 & $0.991-1.018$ & 0.534 & & & \\
\hline eGFR & 0.969 & $0.959-0.980$ & $<0.001$ & 0.990 & $0.978-1.003$ & 0.139 \\
\hline LDL-C & 0.993 & $0.986-1.000$ & 0.056 & & & 0.464 \\
\hline HDL-C & 0.982 & $0.972-0.993$ & 0.001 & 0.993 & $0.975-1.012$ & \\
\hline TG & 1.002 & $1.000-1.004$ & 0.073 & & & 0.980 \\
\hline Apo B/Apo A1 & 2.089 & $1.085-4.022$ & 0.028 & 1.093 & $0.387-3.086$ & 0.147 \\
\hline Lp (a) & 1.007 & $1.000-1.014$ & 0.048 & 1.007 & $0.998-1.016$ & \\
\hline LDL-C/Apo B & 0.184 & $0.068-0.496$ & 0.001 & 0.277 & $0.077-0.994$ & \\
\hline
\end{tabular}

Apo A1; apolipoprotein A1, Apo B; apolipoprotein B, BMl; body mass index, Cl; confidence interval, DBP: diastolic blood pressure, eGFR: estimated glomerular filtration rate, HDL-C; high-density lipoprotein cholesterol, HR; hazard ratio, LDL-C; low-density lipoprotein cholesterol, Lp (a); lipoprotein (a), OR; odd ratio, SBP: systolic blood pressure, TG; triglyceride.

Table 3. Characteristics of individuals stratified by tertiles of the LDL-C/ Apo B ratio.

Data are given as mean $\pm S D$, or as number (\%). Apo A1; apolipoprotein A1, Apo B; apolipoprotein B, BMl; body mass index, CACS; coronary artery calcium score, CCTA; coronary computed tomographic angiography, EF; ejection fraction, eGFR; estimated glomerular filtration rate, HDL-C; high-density lipoprotein cholesterol, LDL-C; low-density lipoprotein cholesterol, Lp (a); lipoprotein (a), TC; total cholesterol, TG; triglyceride

Table 4. Independent predictors for lowest tertile of the LDL-C/ Apo B ratio. 
Variables

$\begin{array}{lll}\begin{array}{l}\text { Total } \\ \text { patients }\end{array} & \begin{array}{l}\text { Tertile } 1 \text { of } \\ \text { the }\end{array} & \begin{array}{l}\text { Tertile } 2 \text { of the } \\ \text { LDL-C/ Apo B }\end{array} \\ (\mathrm{n}=622) & \text { LDL-C/ Apo } & \begin{array}{l}1.0275-1.1666 \\ (\mathrm{n}=210)\end{array} \\ & \text { B } & \\ & \leq 1.0275 & \\ (\mathrm{n}=207) & \end{array}$

Tertile 3 of the pvalue

LDL-C/ Apo

B

$>1.1666$

$(n=205)$

Clinical

characteristics

\begin{tabular}{|c|c|c|c|c|c|}
\hline Age, years & $54.4 \pm 8.9$ & $54.2 \pm 8.1$ & $54.1 \pm 9.6$ & $54.8 \pm 9.1$ & 0.686 \\
\hline Male & $393(63.2)$ & $145(70.0)$ & $138(65.7)$ & $110(53.7)$ & 0.002 \\
\hline Diabetes & $144(23.2)$ & 68 (32.9) & $48(22.9)$ & $28(13.7)$ & $<0.001$ \\
\hline Hypertension & $240(38.6)$ & $89(43.0)$ & 79 (37.6) & $72(35.1)$ & 0.244 \\
\hline Smoking & $208(33.4)$ & 77 (37.2) & 70 (33.3) & $61(29.8)$ & 0.277 \\
\hline SBP (mmHg) & $\begin{array}{l}126.1 \pm \\
18.0\end{array}$ & $\begin{array}{l}127.3 \pm \\
18.9\end{array}$ & $126.8 \pm 18.4$ & $\begin{array}{l}124.1 \pm \\
16.4\end{array}$ & 0.152 \\
\hline $\mathrm{DBP}(\mathrm{mmHg})$ & $75.6 \pm 12.1$ & $76.3 \pm 12.9$ & $76.2 \pm 12.0$ & $74.3 \pm 11.4$ & 0.180 \\
\hline $\operatorname{BMI}\left(\mathrm{kg} / \mathrm{m}^{2}\right)$ & $24.4 \pm 3.64$ & $24.6 \pm 3.87$ & $24.6 \pm 3.63$ & $24.0 \pm 3.40$ & 0.216 \\
\hline $\begin{array}{l}\text { eGFR, }(\mathrm{ml} / \mathrm{min} / 1.73 \\
\left.\mathrm{m}^{2}\right)\end{array}$ & $94.1 \pm 18.9$ & $94.5 \pm 21.4$ & $94.1 \pm 17.7$ & $93.7 \pm 17.4$ & 0.904 \\
\hline EF (\%) & $56.3 \pm 12.2$ & $55.0 \pm 12.9$ & $55.3 \pm 12.7$ & $58.7 \pm 10.5$ & 0.004 \\
\hline $\begin{array}{l}\text { Fasting blood } \\
\text { glucose }\end{array}$ & $\begin{array}{l}114.4 \pm \\
44.5\end{array}$ & $\begin{array}{l}121.6 \pm \\
58.3\end{array}$ & $114.6 \pm 34.7$ & $\begin{array}{l}106.8 \pm \\
35.3\end{array}$ & 0.004 \\
\hline \multicolumn{6}{|l|}{ CCTA } \\
\hline \multicolumn{6}{|l|}{ characteristics } \\
\hline CACS & $\begin{array}{l}198.8 \pm \\
580.1\end{array}$ & $\begin{array}{l}254.9 \pm \\
678.5\end{array}$ & $165.9 \pm 495.4$ & $\begin{array}{l}175.9 \pm \\
550.8\end{array}$ & 0.060 \\
\hline $\mathrm{CAC}>0$ & $305(49.0)$ & $121(58.5)$ & $103(49.0)$ & $81(39.5)$ & 0.001 \\
\hline plaque & $380(61.1)$ & 148 (71.5) & $129(61.4)$ & $103(50.2)$ & $<0.001$ \\
\hline 1 vessel disease & $107(17.2)$ & $37(17.9)$ & $37(17.6)$ & $33(16.1)$ & 0.875 \\
\hline Multivessel disease & $60(9.6)$ & $29(14.0)$ & $15(7.1)$ & $16(7.8)$ & 0.033 \\
\hline Revascularization & $81(13.0)$ & 37 (17.9) & $22(10.5)$ & $22(10.7)$ & 0.040 \\
\hline
\end{tabular}




\begin{tabular}{|lllllll|}
\hline Variables & \multicolumn{3}{l}{ Univariate analysis } & & \multicolumn{3}{l|}{ Multivariate analysis } \\
\hline Age & OR & $95 \% \mathrm{Cl}$ & $\mathrm{p}$-value & OR & $95 \% \mathrm{Cl}$ & p-value \\
\hline Male & 0.998 & $0.979-1.017$ & 0.823 & 0.992 & $0.973-1.013$ & 0.465 \\
\hline Diabetes & 1.575 & $1.103-2.249$ & 0.012 & 1.196 & $0.806-1.775$ & 0.375 \\
\hline Hypertension & 1.319 & $0.938-1.853$ & 0.111 & & & 0.005 \\
\hline Smoking hx & 1.284 & $0.905-1.822$ & 0.161 & & & \\
\hline BMI & 1.021 & $0.976-1.069$ & 0.368 & & & \\
\hline eGFR & 1.002 & $0.993-1.011$ & 0.686 & & & \\
\hline HDL-C & 0.965 & $0.953-0.978$ & $<0.001$ & 0.994 & $0.969-1.012$ & 0.672 \\
\hline TG & 1.006 & $1.004-1.008$ & $<0.001$ & 1.006 & $1.003-1.008$ & $<0.001$ \\
\hline Apo A1 & 0.989 & $0.983-0.995$ & $<0.001$ & 0.990 & $0.978-1.002$ & 0.106 \\
\hline Lp (a) & 1.002 & $0.996-1.009$ & 0.531 & & & \\
\hline
\end{tabular}

Apo A1; apolipoprotein A1, Apo B; apolipoprotein B, BMl; body mass index, Cl; confidence interval, eGFR: estimated glomerular filtration rate, HDL-C; high-density lipoprotein cholesterol, HR; hazard ratio, LDL-C; low-density lipoprotein cholesterol, Lp (a); lipoprotein (a), OR; odd ratio, TG; triglyceride.

\section{Figures}


3696 patients screened

(DCMC CCTA registry, 2013.1 2020.9)

Excluded patients who had

Age $>65$ or LDL-C> $127.5 \mathrm{mg} / \mathrm{dl}: \mathrm{n}=2534$

1162 patients

(Age $\leq 65$ and LDL-C $\leq 127.5 \mathrm{mg} / \mathrm{dl}$ )

622 patients eligible for analysis

Presence of coronary artery plaque according to

traditional cardiovascular risk

factors and lipid profile

Excluded patients who had

$\mathrm{PCl}$ or cardiac surgery: $n=298$

Lipid lowering agents: $n=217$

ESRD: $\mathrm{n}=20$

Motion artic fact: $n=5$

\section{Figure 1}

Enrollment flow chart for analysis. CCTA; coronary computed tomographic angiography, DCMC; Daegu catholic medical center, ESRD; end-stage renal disease, LDL-C; low-density lipoprotein cholesterol, PCl; percutaneous coronary intervention.
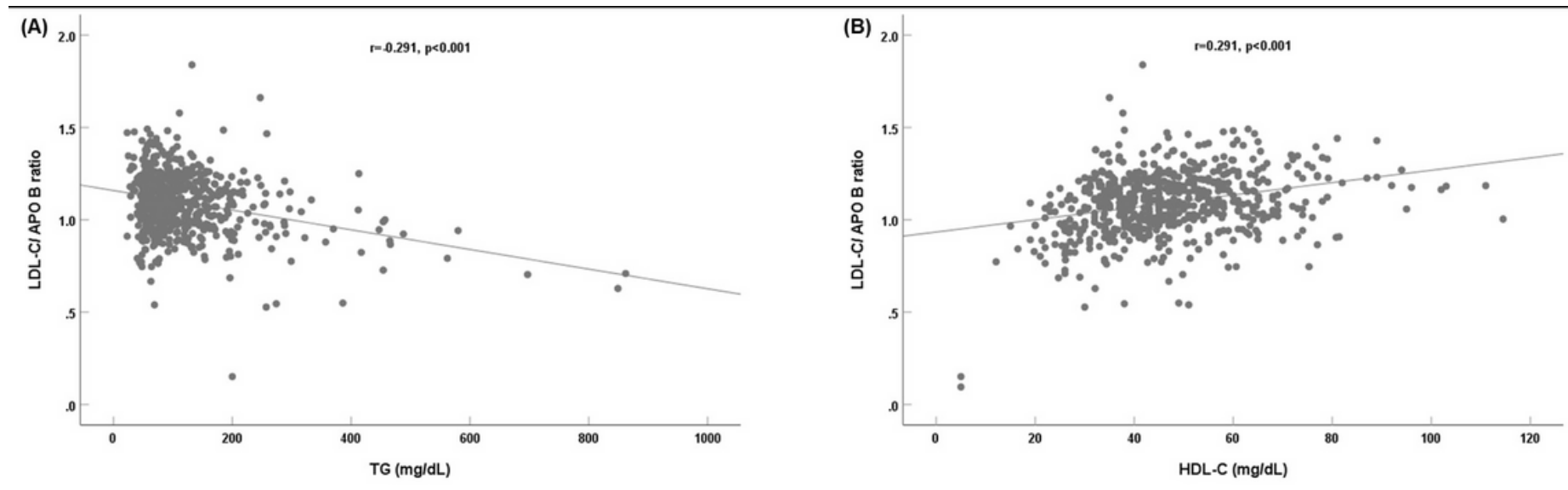
Figure 2

\section{Supplementary Files}

This is a list of supplementary files associated with this preprint. Click to download.

- DATA.xIsx

- ScientificreportSupportingInformation.docx 